möchten. Nach meinen Versuchen an der, wie ich gern zugeben will, wegen ihrer Kleinheit nicht geeigneten Gallenblase des Kaninchen, kounte ich ebenfalls eine Wirkung des faradischen Stromes in keinerlei Weise constatiren. Wohl aber fand sich, dass sehr starke galvanische Ströme direct auf die Wandung applicirt eine deutliche Contraction zu erzielen vermochten.

Die obige Arbeit ist entstanden auf Anregung des Herrn Privatdocenten Dr. Georg Leubuscher in Jena, welcher auch den grössten Theil der Versuche beaufsichtigte. Für die freundliche Hülfe und gütige Unterstützung fühle ich mich gedrungen, demselben auch an dieser Stelle meinen herzlichsten Dank auszusprechen.

\title{
XI.
}

\section{Ueber die Substitution des marantischen Thrombus durch Bindegewebe.}

\author{
Von Dr. E. Heuking \\ ans St, Petersburg \\ und
}

Prof. R. Thoma

in Dorpat.

(Hierzu Taf. VII.)

Ueber die Vorgänge, welche die Umwandlung von Thromben in Bindegewebe bewirken, liegen in der Literatur sehr wenige Angaben vor. Namentlich war es Otto Weber, welcher bei seinen Untersuchungen äber die Organisation von Ligaturthromben einige bedeutsamere Erfahrungen gewonnen hat. Wir werden auf diese, wie auch auf die Arbeiten von Kocher an geeigneter Stelle einzugehen haben. Das Gleiche gilt von einigen späteren Cntersuchungen, welche sich allerdings mehr mit der Verheilung von Verletzungen der Blutgefässe als mit den hier in Betracht kommenden Fragen beschäftigen. Unter diesen Verhältnissen haben wir den Versuch gemacht, an marantischen Thromben 

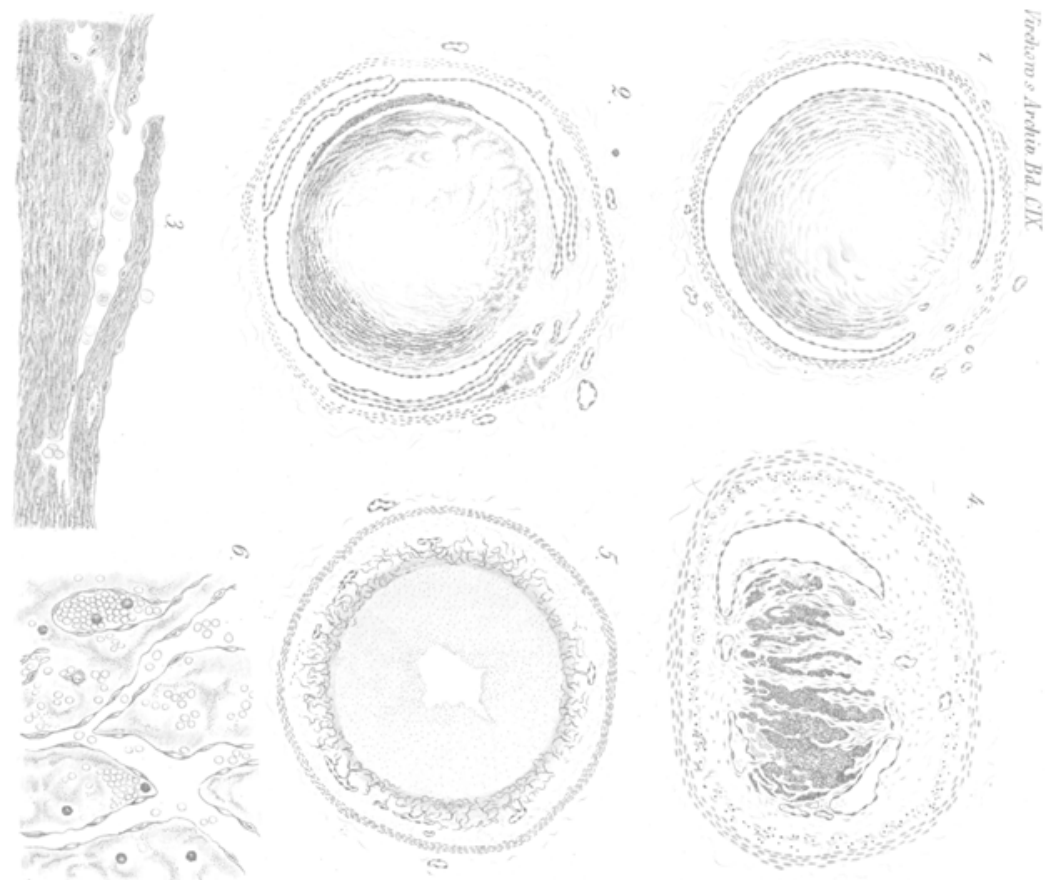

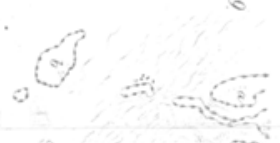

$$
\begin{aligned}
& \text { से } \quad 203
\end{aligned}
$$

$0 \sec ^{2}$ की की

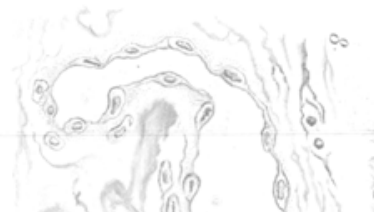

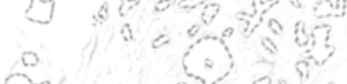

(2) के की हो
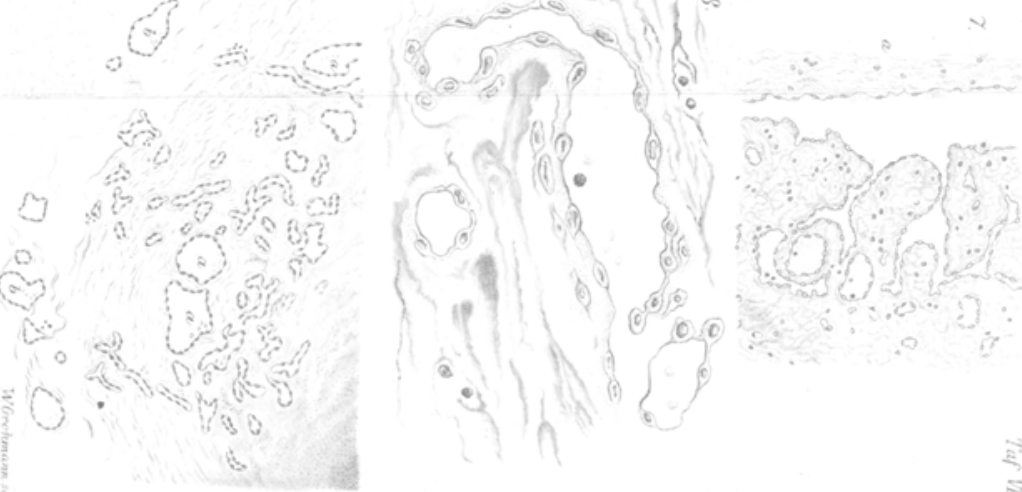

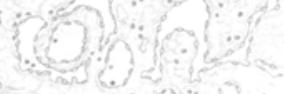

a

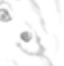


genauer die Vorgänge zu verfolgen, welche sich bei der Umwandlung derselben in Bindegewebe vollziehen.

Das uns zur Verfügung stehende Material bestand aus einer Anzahl von Venen des Ober- und Unterschenkels und der Halsregion, welche sehr ausgedehnte Thromben enthielten. Aus den Sectiọnsprotocollen konnten wir entnehmen, dass diese Venen sämmtlich von ausgesprochen marantischen Individuen herstammten, welche theils an tuberculösen und cariösen Prozessen, theils an Arteriosklerose und Klappenfehlern des Herzens gestorben waren. Die Venen wurden in Müller'scher Flüssigkeit und Alkohol gehärtet, im Celloidin eingebettet und in feine Querschnitte zerlegt. Eine Folge der Härtung in Müller'scher Flüssigkeit war, dass man darauf verzichten musste, die Erscheinungen der indirecten Kern- und Zelltheilung zu verfolgen. Für eine erste Untersuchungsreihe aber wurde auf diesem Wege der schwerwiegende Vortheil errungen, dass sich die in den Venen enthaltenen Reste frischen Blutes sehr scharf von älteren Gerinnungen unterscheiden liessen, denn bekanntlich eignet sich die Müller'sche Flüssigkeit in hohem Grade zur Conservirung der rothen Blutkörper.

Nach der Zerlegung der Präparate in Stufenschnitte wurden dieselben mit Alauncarmin gefärbt und in Canadabalsam eingebettet. Es ergab sich sodann zunächst, dass alle vorliegenden Thromben mehr oder weniger deutlich die Charaktere geschichteter Thromben aufwiesen. Dieselben waren zufolge der klinischen Beobachtung sämmtlich als ältere Thromben zu bezeichnen, welche drei bis acht Wochen vor dem Tode entstanden waren. Diese Zeitangaben gelten allerdings nur für den Thrombus im Allgemeinen, da nicht ausgeschlossen werden konnte, dass einzelne Abschnitte desselben nachträglich durch fortgesetzte Gerinnung, kürzere Zeit vor dem Tode sich bildeten. Es erklärt sich aber durch diese Verhältnisse, wenn wir keinerlei Angaben machen über die Frage, welche Rolle die Blutplättchen bei der Gerinnung spielten. Die concentrischen Schichten der von uns untersuchten Thromben bestanden in der Regel aus einer mehr oder weniger hyalinen oder feinkörnigen Masse, welche mit Alauncarmin sich sehr intensiv färbte und entsprechend der Schichtung eine feine concentrische Streifung aufwies. Zuweilen 
war diese Masse auch vollkommen homogen und hyalin und dann in der Regel von feinen Spalt- und Kanalsystemen durchsetzt. Sie hatte den Charakter des von Langhans ${ }^{1}$ ), v. Recklinghausen ${ }^{2}$ ), und Anderen beschriebenen "kanalisirten Fibrins" angenommen. In diese Spalten waren nicht selten von Neuem aus der Umgebung her die Elemente des frischen Blutes eingedrungen. An anderen Orten dagegen enthielten die Kanalsysteme des hyalin umgewandelten Thrombus feinkörnige gelbbraune Massen, welche man deuten möchte als Zerfallsproducte der nachträglich in die Kanäle eingedrungenen rothen Blutkörper. In relativ geringerer Ausdehnung zeigten die untersuchten Thromben noch deutlich ihre ursprüngliche Structur. Es handelte sich in diesem Falle entweder um Fibrinmassen, welche zahllose Leucocyten enthielten und somit mit den weissen Thromben von Zahn übereinstimmten oder um rothe Cruormassen, rothe Thromben, welche neben den Fibrinfäden die zelligen Elemente des Blutes in ihrem gewöhnlichen Mischungsverhältnisse aufwiesen.

Für die Untersuchung mit unbewaffnetem Auge bot das uns zur Verfügung stehende Material den Eindruck vollständig obturirender Thromben. Bei der mikroskopischen Untersuchung jedoch stellten sich häufig andere Verhältuisse heraus. An Quer- und Längsschnitten, die aus solchen Partien der thrombosirten Venen angefertigt wurden, welche bei der Untersuchung mit unbewaffnetem Auge das Gefässlumen vollständig ausfüllende Gerinnsel zu enthalten schienen, fanden sich bei mikroskopischer Untersuchung sehr häufig Spalten und Hohlräume zwischen der Intima und den Thrombusmassen.

Die Form und die Ausdehnung dieser den Thrombus umgebenden Spalträume ist eine sehr wechselnde; so weisen einzelne Abschnitte der thrombosirten. Venen nur äusserst kleine, bald ring- oder halbmondförmige, bald sehr unregelmässig gestaltete zwischen Intima und Thrombusmasse gelagerte Lücken auf. Durch die Vergleichung mehrerer auf einander folgender

1) Langhans, Untersuchungen über die menschliche Placenta. Archiv f. Anatomie u. Physiologie. Anatomische Abtheilung. 1877.

2) v. Recklinghausen, Tageblatt der Naturforscherversammlung in Baden-Baden 1879. Handbuch d. Allg. Pathologie des Kreislaufes u. der Ernährung. Deutsche Chirurgie. 1883. 
Schnitte kann man sich davon überzeugen, dass diese lücken nicht Durchschnitte von vollständig abgeschlossenen Hohlräumen sind, sondern dass sie durch vielfache, nach allen Richtungen sich erstreckende Ausläufer unter einander zusammenhängen und auf diese Weise ein weitverzweigtes, über grössere Strecken der thrombosirten Venen sich verbreitendes, zwischen Thrombusoberfiäche und Venenwand eingeschaltetes Spaltensystem darstellen. Von den beschriebenen kleinsten Anfängen an finden sich die Spalten und Lücken in den verschiedensten Grössenabstufungen bis hinauf zu solchen, welche unter der Form sicheloder halbmondförmiger Hohlräume die Hälfte oder drei Viertel oder selbst noch grössere Abschnitte der Peripherie des Thrombus umspannen, so dass letzterer nur mit einem sehr kleinen Theile seines Umfanges der Venenwand anliegt. (Vergl. Fig. 1 und 2.)

Mit der grössten Constanz lassen sich in allen diesen peripherisch zwischen Thrombus und Venenwand liegenden Lücken und Spalträumen, sowohl in den kleinsten wie auch in den umfangreichsten, Spuren ganz frischen Blutes nachweisen. Die rothen Blutkörperchen, theils einzeln, theils in Haufen zusammenliegend, weisen vollständig scharfe, unveränderte Conturen auf; an manchen Stellen werden sie von einem feinen, aus sehr dünnen Fibrinfäden bestehenden Netzwerke umsponnen. Auch einzelne farblose Blutkörperchen, durch ihren grösseren Umfang, durch ihre körnige Beschaffenheit und durch ihre carmingefärbten Kerne leicht kenntlich, findet man zerstreut in den Haufen rother Blutkörperchen. - Bezüglich der Entstehung dieses Systems von Lücken sind zwei Möglichkeiten im Auge zu behalten. In allen von uns untersuchten Fällen handelte es sich um sehr ausgedehnte Thromben. Die Beschaffenheit der Gerinnselmassen zeigte dabei vielfachen Wechsel, so dass man daraus schliessen musste, dass eine Mehrzahl klappen- oder wandständiger Thromben durch fortschreitendes Wachsthum mit einander direct in Verbindung getreten. waren. Bei einer derartigen Ausbreitungsweise der Thromben kann es wohl vorkommen, dass sie nicht überall das Gefässlumen ganz gleichmässig ausfüllen, so dass einzelne Abschnitte der thrombosirten Venen für den Blutstrom durchgängig bleiben. 
Ein grosser Theil der den Thrombus umgebenden Spalten hat aber höchst wahrscheinlicher Weise seine Entstehung einem anderen Vorgange zu verdanken. Es ist eine längst beobachtete und häufig constatirte Thatsache, dass ein den Querschnitt eines Gefässlumen vollständig ausfüllendes Gerinnsel in seinen einzelnen Theilen sowohl, wie auch als Ganzes mit der Zeit schrumpft und sich auf ein kleineres Volum reducirt. Hierdurch entstehen entweder im Innern des Gerinnsels, zwischen seinen einzelnen Schichten, Spaltbildungen; oder aber es erfolgt eine hald auf grössere, bald auf kleinere Partien der Thrombusoberfläche sich erstreckende Ablösung der letzteren von der Gefässwand, wobei durch das sofort nachdrängende Blut eine Abhebung der betreffenden Gefässwandstrecke rom Thrombus bewirkt wird. Schon von Virchow ${ }^{1}$ ) wurde hervorgehoben, dass durch diesen Prozess eine Art partieller Wiedereröffnung des thrombosirten Gefässlumen für den Blutstrom herbeigeführt werden kann. Im einzelnen Falle ist es jedoch zuweilen schwer nachzuweisen, ob eine circuläre Spalte, wie sie z. B. in den Figg. 1 und 2 zu sehen ist, -ihre Entstehung einer Retraction des Gerinnsels verdankt, oder ob hier von vornherein der Verschluss des Venenlumen kein vollständiger war, sondern ein solcher für die Untersuchung mit unbewaffnetem Auge nur vorgetäuscht wurde, denn wie ich schon in den einleitenden $\dot{W}_{\text {orten }}$ gesagt, für das unbewaffnete Auge handelte es sich hier in der That um obturirende Thromben.

$\mathrm{Zu}$ diesen entweder von vornherein bestehenden, oder erst nachträglich wieder eröffneten Abschnitten des Gefässlumen verschafft sich das Blut auf verschiedenen Wegen Zutritt. In einzelnen Abschnitten des Lumen, welche niemals vollständig von den Gerinnselmassen verlegt worden waren, wird die Blutcirculation überhaupt nicht ganz aufgehoben gewesen sein. Den neueröffneten Bahnen wird es hingegen zweifelsohne sowohl durch einige der Thrombosirung entgangene Seitenäste, als auch aus noch durchgängigen Partien der thrombosirten Gefässe zuströmen.

Die besprochenen Lagerungsverhältnisse der Thromben zur Venenwand scheinen nicht ohne Beziehungen zu gewissen anatomischen Structurveränderungen der letzteren zu sein. Eine ge-

1) R. Virehow, Gesammelte Abhandlungen. S. 235. 
ringe fibröse Verdickung der Intima fand sich fast durchweg an allen Abschnitten der von uns untersuchten Venen. Sehr häufig - gewahrt man aber gerade an denjenigen Stellen, an welchen der Thrombus der Intima fest anliegt, eine besonders starke Dickenzunahme der letzteren, beruhend auf der Ausbildung einer mehr oder weniger mächtigen Schicht fibrösen, mässig zellreichen Bindegewebes. Je nachdem nun der Thrombus auf einem gegebenen Querschnitte blos an einer oder an mehreren Stellen seiner Peripherie mit der Venenwand in Berührung verblieben ist, wechselt auch die Ausdehnung der von den endophlebitischen Verdickungen bevorzugten Intimaabschnitte. Wenn aber die Bindegewebswucherung in der Intima vorzüglich an denjenigen Stellen in Erscheinung tritt, an welchen der Thrombus mit der Intima in unmittelbarer Berührung steht, so bleibt sie doch nicht streng auf diese beschränkt, sondern verbreitet sich auch auf die angrenzenden Abschnitte der Intima. In kleineren Venen erscheint sogar die Intima nicht selten im ganzen Umfange des Gefässes auf grössere Strecken hin bindegewebig verdickt.

Die weitere Untersuchung lehrt, dass diese bindegewebige Verdickung der Intima im Allgemeinen um so deutlicher hervortritt, je älter der Thrombüs zufolge der klinischen Beobachtung ist, und je mehr derselbe auch in seinem Innern Blutgefässe und Bindegewebe enthält. Es ist indessen, bei den erheblichen Schwierigkeiten, welche sich der Feststellung des Alters eines Thrombus in den Weg legen, kaum möglich in dieser Beziehung sehr zuverlässige Ergebnisse zu gewinnen, wenn man nicht über ein viel grösseres Material verfügt. Dieses allein würde gestatten, genauer die Beziehungen zwischen der Thrombose und der Endophlebitis fibrosa festzustellen. Gegenwärtig kann man nur darauf hinweisen, dass auch die marantische Thrombose wahrscheinlicher Weise endophlebitisch erkrankte Venen bevorzugt, während andererseits unzweifelhaft auch die Thrombose selbst zu einer bindegewebigen Verdickung der Intima führt.

Die beschriebenen Contactstellen zwischen Thrombus and Venenwand sind für den gesammten Organisationsvorgang, welcher sich in den Thromben abspielt, von der grössten Wichtigkeit. Sie sind die Ausgangsstellen, von denen aus alle die geweblichen Vorgänge ihren Anfang nehmen, welche in ihrem 
weiteren Ablaufe zu einer Substitution der intravasculären Gerinnselmassen durch wohlorganisirtes, Blutgefässe enthaltendes Bindegewebe führen. Diese Vorgänge lassen sich jedoch behufs Vereinfachung der Darstellung in zwei Gruppen gliedern. Es zeigt sich nehmlich, dass die Substitution des Thrombus durch Bindegewebe entweder beginnt mit einer Wucherung des Endothels der thrombosirten Vene, oder aber mit einer Wucherung des Endothels der Vasa vasorum. Diese beiden Modificationen des Vorganges combiniren sich in der mannichfaltigsten Weise. Es erscheint indessen zweckmässig sie zunächst getrennt zu besprechen.

I. Bindegewebsneabildung und Vascularisation, ausgehend von dem Endothel der thrombotischen Vene.

Am einfachsten gestalten sich die hier zu besprechenden Verhältnisse in solchen Fällen, in welchen der Thrombus nur an einer einzigen beschränkten Stelle seines Umfanges mit der Venenwand in Berührung geblieben ist. Wir legen daher unserer Darstellung zunächst den in Fig. 1 abgebildeten Querschnitt zu Grunde. Derselbe ist einer thrombosirten Vena femoralis superficialis entnommen. Der Thrombus lag im Celloidinpräparat in grosser Ausdehnung lose im Venenlamen, so dass er in vielen Schnitten durch eine circuläre, Reste von frischem Blute führende Spalte von der Venenwand getrennt erscheint. Von Stelle zu Stelle aber näherte er sich der einen Wand der Vene um rnit dieser in innige Verbindung zu treten. Dieser Wechsel zwischen freier Lagerung des Thrombus in der Gefässlichtung und circumscripter Verwachsung desselben mit der Gefässwand, wiederholt sich innerhalb der hier in Rede stehenden Gefässstrecke einige Male. Mit Hülfe von Längsschnitten überzeugt man sich aber, dass die Berührungspunkte zwischen Thrombus und Gefässwand nicht nur in circulärer, soudern auch in longitudinaler Richtung eine sehr geringe Ausdehnung besitzen.

Der in Fig. 1 abgebildete Querschnitt ist durch eine der Contactstellen dieses Thrombus gelegt. Dieselbe findet sich an einer Stelle der Intima der Vene, welche, wie gewöhnlich, sich durch eine stäkere endophlebitische Verdickung auszeichnet. Das Bindegewebe der verdickten Intima setzt sich aber continuirlich 
auf die Oberfläche des Thrombus fort und umgreift diesen von beiden Seiten her als heller bindegewebiger Saum, welcher sich in dem Maasse verjüngt, wie er sich von der Contactstelle entfernt. Zuweilen wird auf diesem Wege der ganze Umfang des Thrombus eingescheidet; ofters bleiben die der Contactstelle gegenüber liegenden Theile der Thrombusoberfläche frei. Der bindegewebige Randsaum ist aber auch auf vielen Schnitten nachweisbar, welche die Contactstellen nicht treffen, wo somit der Thrombus frei im Venenlumen liegt. Mit Hülfe von Stufenschnitten überzeugt man sich, dass die Bindegewebswucherung von den Contactstellen aus nicht nur in circulärer, sondern auch in longitudinaler, der Gefässaxe paralleler Richtung die Thrombusoberfläche weithin überzieht. Zugleich bemerkt man, dass auch auf dem Längsschnitte der thrombosirten Vene der bindegewebige Randsaum um so dünner wird, je weiter er sich von der Contactstelle entfernt. Man gewinnt auf diesem Wege unmittelbar die Anschauung, dass die bindegewebige Einscheidung des Thrombus von den Contactstellen ausgeht. Dabei ereignet es sich dann sehr häufig, dass die von zwei getrennten Contactstellen herstammenden Bindegewebswucherungen mit einander verschmelzen, und eine zusammenhängende Lage bilden, welche sich auf den grössten Theil der Thrombusoberfläche erstreckt.

Die histologische Structur des bindegewebigen Randsaumes stimmt in allen Beziehungen überein mit der Structur der Bindegewebsschichten der endophlebitisch verdickten Intima. Es handelt sich hier um ein concentrisch zur Oberfläche des Thrombus gestreiftes Bindegewebe, welches in einer lichten Intercellularsubstanz zahlreiche verästigte Zellen enthält. Letztere erscheinen auf Querschnitten der thrombosirten Vene in der Regel als spindelförmige Gebilde. Doch überzeugt man sich durch Handhabung der Stellschraube des Mikroskops, wie durch Längsschnitte, dass man es mit flach ausgebreiteten, ovale Kerne enthaltenden Zellen zu thun hat, deren breite Flächen parallel der Oberfläche des Thrombus liegen.

Auf der freien, dem halbmondförmigen Gefässlumen zugewendeten Fläche des Bindegewebssaumes, welcher die Thromben umhüllt, bemerkt man eine wohlcharakterisirte, zusammenhängende Endothelschicht (Fig. 1). Dieselbe bedeckt in allen Fällen 
die ganze Ausdehnung dieses bindegewebigen Randsaumes. In den früheren Entwickelungsstadien, in welchen der bindegewebige Randsaum einzelne Stellen des Thrombus noch nicht überkleidet hat, reicht sogar regelmässig dic Endothelschicht noch eine Strecke weiter über die nicht mit Bindegewebe überzogenen $\mathrm{Ab}$ schnitte des Thrombus, wie dies in der genannten Abbildung ersichtlich ist. Dagegen konnte man niemals beobachten, dass der Bindegewebssaum die Grenzen der Endothelschicht überschritt. An den Contactstellen endlich geht diese Endothelschicht continuirlich über in die endotheliale Auskleidung der Venenintima. Die gesammte topographische Anordnung der Randwucherung führt zu der Vermuthung, dass vor Allem das Endothel der Vene den geschrumpften Thrombus überwuchere und dass sodann von diesem aus eine Bindegewebsneubildung sich einleite, welche zur Entwickelung des bindegewebigen Randsaumes führe.

Die grosse Bedeutung, welche den soeben geschilderten topographischen Verhältnissen zukommt, rechtfertigt es, noch einige Einwürfe zu widerlegen. Es wäre denkbar, dass die Endothelschicht, welche den Thrombus überklejdet, nichts Anderes wäre, als das Endothel der Venenintima, welches bei der Schrumpfung des Thrombus an dem letzteren haften geblieben und auf diese Weise von der Intimaoberfäche abgehoben worden wäre. Diesem Einwande gegenüber genügt es darauf hinzuweisen, dass in allen Schnitten ausser dem den Thrombus überziehenden Endothel auch das Endothel der Venenintima vollkommen erhalten war. Ferner könnte man sich veranlasst sehen, die Existenz einer bindegewebigen Randzone zu beanstanden und zu behaupten, dass sie vorgetäuscht worden sei durch Theile einer Venenklappe. Ein Blick auf die Fig. 2 jedoch nimmt einem derartigen Einwande jede Berechtigung. Hier sind beide Venenklappen im Durchschnitt getroffen; die eine, untere, liegt der Venenwand nahezu vollständig an, enthält nur einige Reste ganz frischen Blutes und ist in ihrer ganzen Ausdehnung von dem Thrombus durch das halbmondförmige Lumen getrennt; die andere, obere, schliesst in der ihr zugehörigen Tasche ein älteres, zum Theil durch fibröses Bindegewebe substituirtes Gerinnsel ein. Der im Lumen gelegene Thrombus besitzt ausserdem seine bindegewebige Randzone, 
welche mit dem einen Klappensegel verwachsen ist. Alle freien, dem Restlumen der Vene zugewendeten Flächen aber sind mit Endothel bekleidet. Nur linkerseits findet sich am Thrombus eine kleine endothelfreie Stelle und diese ist auch in so ferne ausgezeichnet, als sich hier eine neue Schicht von Gerinnungen auf der bindegewebigen Randzone des Thrombus abgelagert hat. Diese neue Gerinnung aber ist zum Theil wiederum mit Endothel bekleidet, während das Endothel an der entsprechenden Stelle der bindegewebigen Randzone des Thrombus fehlt. Wir möchten dieser Besonderheit des gegebenen Präparates keine grössere Bedeutung beimessen, weil der Befund nicht eindeutig ist. Doch kann man auf Grund anderer analoger Beobachtungen mit zie̋mlicher Bestimmtheit die Vermuthung aussprechen, dass hier weder agonale noch postmortale Veränderungen vorliegen. Indessen dürfte unabhängig von der Deutung dieses secundären Gerinnsels, das der Fig. 2 zu Grunde liegende Präparat klar erweisen, dass bei der obigen Schilderung der topographischen Verhältnisse keine. Irrthümer. begangen wurden.

Wendet man sich nun zu den Einzelheiten der histologischen Structur der den Thrombus umgebenden Randwucherung, so bemerkt man an vielen Stellen der Ietzteren unmittelbar. unter dem Endothel eigenartige Zellen, welche weder mit den Endothelien noch mit den früher geschilderten Bindegewebszellen vollständig übereinstimmen. Es sind dies ovale und unregelmässig länglich gestaltete Zellen mit grossen Kernen, welche sich namentlich durch ihre gedrungenere Gestalt von den Bindegewebs- und Endothelzellen unterscheiden. Sie können indessen auch nicht mit Wanderzellen and lymphatischen Elementen in Vergleich gebracht werden, dazu sind sie viel zu gross. Wir wollen sie vorläufig als junge, unentwickelte Formen von Bindegewebszellen betrachten und zunächst feststellen, dass sie unmittelbar unter dem Endothel der bindegewebigen Randzone am häufigsten vorkommen und hier den Endothelzellen in der Regel räumlich sehr nahe gerückt sind. Zwischen denselben und dem Endothel kann mau nur wenig homogene Intercellularsubstanz nachweisen.

Theils an diese eigenartigen Zellformen, theils direct an das Endothel grenzen die äussersten Schichten der bindegewebigen Randzone. Diese erscheinen sehr zellreich und arm an fein- 
faseriger, concentrisch zur freien Oberfläche des Thrombus' gestreifter Intercellularsubstanz. Die Zellen dieser äussersten Lamellen des bindegewebigen Randsaumes lassen zuweilen in Beziehung auf ihre Gestalt und auf ibre Kerne eine deutliche Uebereinstimmung mit den soeben erwähnten unentwickelten Formen der Bindegewebszellen erkennen. Grossentheils aber weisen sie bereits die Eigenschaften der verzweigten Bindegewebszellen auf, welche typisch in allen neugebildeten Bindegewebsschichten der Intima von Venen und Arterien wiederkehren. In etwas grösserer Entfernung von dem Endothelüberzug und somit näher dem Blutgerinnsel verliert dieses Bindegewebe der Randwucherung seinen grossen Zellreichthum, indem die feinfaserige Intercellularsubstanz in grösseren Mengen hervortritt. Man überzeugt sich, dass die Intercellularsubstanz in vollkommen regelmässiger Weise eine allmähliche Zunahme erfährt in dem Maasse, wie man sich den tieferen, dem Thrombus unmittelbar angrenzenden Schichten nähert. Diese Grenze ist in manchen Fällen scharf und glatt, häufig jedoch von sehr unregelmässiger Beschaffenheit, in Folge der später zu schildernden Vorgänge der Gefäss- und Bindegewebsneubildung in den peripherischen Theilen der Thrombusmassen.

Auch diese Verhältnisse sprechen dafür, dass die Anbildung neuer Zelllagen in der bindegewebigen Randwucherung vorzugsweise von der endothelialen Bekleidung ihren Ausgang nimmt. Daraus ergiebt sich nothwendiger Weise, dass die älteren Schichten des bindegewebigen Saumes oder Mantels, welcher den Thrombus umhüllt, allmählich in die Tiefe rücken in dem Maasse als Seitens des Endothels neue Bindegewebsschichten apponirt werden. Es lässt sich diese Erscheinung direct vergleichen mit den Befunden von Thoma ${ }^{1}$ ), welcher nachweisen konnte, dass bei der Arteriosclerosis nodosa die jüngeren bindegewebigen Verdickungsschichten der Intima sich unter dem Endothel an die Innenfläche der älteren Bindegewebsschichten anlegen. Indessen kommen auch in der ganzen Dicke des binde-

1) R. Thoma, Ueber die Abbängigkeit der Bindegewebsneubìlung in der Arterienintima von den mechanischen Bedingungen des Blutumlaufes. Fünfte und sechste Mittheilung. Die Arteriosclerosis nodosa. Dieses Archiv Bd. 105. S. 1 u. 197. Taf. II. Fig. 13. 
gewebigen Randsaumes des Thrombus, allerdings in sehr geringer Zahl, jene eigenartigen Zellen vor, welche wir oben als unentwickelte Formen von Bindegewebszellen bezeichneten. Es ist daher nicht in Abrede zu stellen, dass der Bindegewebsmantel des Thrombus auch in seinem Innern an Masse zunimmt durch Theilung der bereits fertig gebildeten Bindegewebszellen. Doch mussten wir leider, in Anbetracht der angewendeten Härtungsmittel darauf verzichten, die Bilder der indirecten Kerntheilung aufzusuchen. Indessen erläutern sich diese Verhältnisse vollständig durch den von Thoma ${ }^{1}$ ) geführten Nachweis der indirecten Theilung der Kerne und des Protoplasma der fixen Zellen in den bindegewebigen Verdickungen, welche in der Intima der Arterien von Amputationsstümpfen sich bilden.

Nach unserem Dafürhalten erscheint es wahrscheinlich, dass die mehrfach genannten eigenartigen Zellen, welche als Jugendformen von Bindegewebszellen bezeichnet wurden, entstehen zum grösseren Theile durch Proliferation der Endothelzellen, welche den Thrombus und seinen bindegewebigen Randsaum umhüllen, zum kleineren Theile durch Proliferation der bereits vollkommen entwickelten Bindegewebszellen des Randsaumes. Es würden sodann diese jugendlichen Zellen Intercellularsubstanz ausscheiden und damit zugleich sich in typische Bindegewebszellen umwandeln.

Die soeben erwähnten unentwickelten Formen von Bindegewebszellen besitzen eine gewisse Aehnlichkeit mit den Fibroblasten Ziegler's²), welche dieser Autor entweder aus der Theilung präexistenter Gewebselemente ableitet oder aber als weitere Entwickelungsstufen von emigrirten Wanderzellen deutet. Es soll daher darauf aufmerksam gemacht werden, dass in diesen Gewebswucherungen im Bezirke des bindegewebigen Randsaumes des Thrombus, Wanderzellen und lymphoide Elemente an vielen Stellen gänzlich fehlen. Wo sie aber vorkommen, treten sie

1) Thoma, Das Verhalten der Arterien in Amputationsstümpfen. Dieses Archiv Bd.95. S. 320.

2) E. Ziegler, Experimentelle Untersuchungen über die Herkunft der Tuberkelelemente. 1875. Untersuchungen über pathologische Bindegewebs- und Gefässneubildung. 1876.; ferner: Lehrbuch der patholog. Anatomie. Vierte Auflage. Bd. I. S. 114. 
nur äusserst spärlich auf. Es muss daher als unwahrscheinlich bezeichnet werden, dass den Wanderzellen hier eine bedeutsamere Rolle bei der Bindegewebsneubildung zukommt.

Diese Ergebnisse finden eine weitere Bestätigung, wenn man die Aufmerksamkeit denjenigen Theilen der bindegewebigen Randwucherung zuwendet, welche am weitesten von den Contactstellen entfernt sind und demgemäss nur aus sehr dünnen Gewebsschichten bestehen. Hier, wo der bindegewebige Mantel des Thrombus sich allmählich zuschärft und schliesslich in die einfache Endothelschicht ausläuft, lassen sich die jüngsten Stadien der Bindegewebsneubildung relativ leicht verfolgen. Je mehr in diesen Abschnitten der Randzone die Masse des Bindegewobes abnimmt, desto mehr tritt die anfangs noch sehr massige Intercellularsubstanz an Menge zurück, und desto grösser wird der Gehalt des Bindegewebes an zelligen Elementen. Schliesslich bleiben unter dem Endothel nur drei oder zwei Reihen von Zellen übrig, die von einander nur durch eine spärliche Menge hyaliner Intercellularsubstanz getrennt werden. Die Gestalt dieser Zellen ist auf dem Durchschnitt durchweg keine spindelförmige, sondern eine mehr ovale.

Als letzte Ausläufer der unter dem Endothel liegenden Bindegewebsschicht erscheinen schliesslich vereinzelte, hart an der Endothelzellenreihe liegende Elemente von dem Charakter der oben erwähnten jugendlichen Bindegewebszellen.

Des Interesses wegen, welche solche fast auf jedem Schnitte wiederkehrende Stellen boten, haben wir dieselben mit der grössten Aufmerksamkeit untersucht. Nirgends in den benachbarten Gerinnselschichten haben wir Spuren einer Gewebsbildung nachweisen können, zu der diese unmittelbar unter dem Endothel liegenden jungen Bindegewebszellen in Beziehung gebracht werden konnten. Allerdings fanden sich in den Fibrinmassen des Thrombus stellenweise Zellen vom Charakter der farblosen Elemente des Blutes. Diese liessen zum Theil die Erscheinungen des körnigen Zerfalls erkennen. Niemals aber waren wir im Stande, Uebergangsformen zwischen den lymphoiden Zellen und den jugendlichen, unter dem Endothel gelegenen Bindegewebszellen nachzuweisen. Es fehlte somit jeder Anhaltspunkt, letztere für Ablömmlinge der lymphoiden Zellen zu deuten. 
Dagegen spricht die eigenartige Lage dieser jugendlichen Bindegewebszellen entschieden für ihre Abstammung von den Endothelien. Denn unter den gegebenen Verhältnissen sind nur vier Möglichkeiten gegeben. Die erste Möglichkeit, der Entstehung dieser Zellen aus den ungeformten Gewebssäften durch Urzeugung halten wir für undiscutirbar, um so mehr, da auch die topographischen Verhältnisse gegen eine solche Annahme sprechen. E bleiben dann die Zellformen zu besprechen, von denen die Zellvermehrung ausgehen könnte: die lymphoiden Wanderzellen, die Zellen der Endothelschicht und endlich die Bindegewebszellen des den Thrombus umhüllenden Mantels oder in letzter Instanz der Venenintima. Oben versuchten wir die lymphoiden Zellen auszuschliessen. Die bereits fertig gebildeten Bindegewebszellen aber kommen hier gleichfalls nicht in Betracht, weil diese weit abliegen von den in Rede stehenden jugendlichen Zellen. Auch wurde oben darauf hingewiesen, dass die Bindegewebsneubildung niemals die Grenzen des endothelialen Ueberzuges des Thrombus überschreitet, was doch sicherlich zu erwarten wäre, wenn die Bindegewebsneubildung unabhängig vom Endothel sich vollziehen würde. Es bleiben somit auf dem Wege der Exclusion nur die Endothelzellen übrig. Und dafür, dass diese die Generatoren sind, dafür spricht zunächst der Umstand, dass die jugendlichen Bindegewebszellen sich hier ausschliesslich in unmittelbarer Nähe der Endothelzellenlage finden an Stellen, wo Zellen anderen Charakters auf weite Strecken fehlen. Und in gleichem Sinne ist es zu deuten, wenn oben nachgewiesen werden konnte, dass die Endothelbildung auch räumlich immer der Bindegewebsneubildung vorausgeht. Dieses Ergebniss erleidet unseres Erachtens keine Beeinträchtigung dadurch, dass an anderen Stellen in der Masse des Bindegewebsmantels wahrscheinlicher Weise auch die bereits fertigen Bindegewebszellen sich von Nenem theilen und junge Bindegewebszellen entstehen lassen. Auch ist darauf hinzuweisen, dass die Untersuchung der Vernarbung von ligirten und in anderer Weise verletzten Arterien viele Beobachter zu ähnlichen Frgebnissen bezüglich der Genese von Bindegewebszellen geführt hat. Bei einer früheren Gelegenheit ${ }^{\prime}$ ), bei welcher der

1) Heuking, Ueber d. Organisation des Thrombus. Diss.inaug. Dorpat 1886. Archiv f. pathol. Anat. Bd. CIX. Hft. 2. 
eine von uns bereits eine vorläufige, wenn auch sehr kurze Mittheilung über diese Untersuchungen machte, wurde versucht die hier vorzugsweise in Betracht kommenden Verdienste der Arbeiten von (Cohn ${ }^{3}$, , Waldeyer ${ }^{2}$ ), Thiersch ${ }^{3}$ ), RiedeI ${ }^{4}$ ), Baumgarten ${ }^{5}$ ), Auerbach ${ }^{6}$ ), Pfitzer ${ }^{7}$ ), Raab ${ }^{8}$ ), Zahn ${ }^{9}$ ), $\mathrm{Pick}^{10}$ ) und Anderer zu beleuchten, und ist demgemäss auf jene Darstellung zu verweisen. Aus diesen Arbeiten geht mindestens mit grosser Wahrscheinlichkeit hervor, dass die Endothelzellen der Blutbahn im Stande sind, Bindegewebszellen zu erzeugen.

Mit der Bildung der bindegewebigen Randwucherung ist aber die Bedeutung der den Thrombus überwachsenden Endotheltapete für die Substitution des Thrombus durch Bindegewebe noch keineswegs erschöpft. Ihr fällt noch die Aufgabe zu, einen sehr wesentlichen Beitrag zur Umbildung der oberflächlichen und unter Umständen auch der tieferen Schichten des Thrombus zu liefern.

Untersucht man aufmerksam diejenigen Abschnitte der Thrombusoberfläche, welche nur mit einem Endothelhäutchen bedeckt sind, so erscheinen an vielen Stellen. Lücken in der Continuität dieses Häutchens. Doch sind diese Continuitäts-

1) Cohn, Klinik der embolischen Gefässkrankheiten. Berlin 1860. S. 91.

2) Waldeyer, Zur pathologischen Anatomie der Wundkrankheiten. Dieses Archiv Bd. 40. 1867.

3) Thierseb, Die feineren anatomischen Veränderungen nach Verwundung der Weichtheile. Handbuch d. allg. u. speciellen Chirurgie von Pitha u. Billrotb. Bd.I. Abth. 2. S. 549.

4) Riedel, Entwickelung der Narbe im Blutgefäss nach der Unterbindung. Deutsche Zeitscbr. f. Chirurgie. Bd.6. 1876.

5) Baumgarten, Die sogenannte Organisation des Thrombus. Leipzig 1877.

6) Auerbach, Ueber die Obliteration der Arterien nach Ligatur. Diss. inaug. Bonn 1877.

7) Pfitzer, Ueber den Vernarbungsvorgang an durch Schnitt verletzten Blutgefässen. Dieses Archiv Bd. 77. 1877.

8) Raab, Entwickelung der Narbe im Blutgefäss etc. Arch. f. klinische Chirurgie. Bd. 23. 1879.

9) Zahn, Untersuchungen über die Vernarbung von Querrissen der Arterienintima und Media nach Umschnürung. Dieses Archir Bd.96. 1884.

10) Pick, Ueber die Rolle der Endothelien bei der Endarteritis post ligaturam. Zeitschrift für Heilkunde. Bd. VI. 1886. 
unterbrechungen in der That nur scheinbare; denn bei näherer Prüfung erweist es sich, dass die Endotheltapete hier nicht plötzlich abbricht, sondern vielmehr längs der Umwandungen benachbarter Gerinnseltheile sich in die Tiefe senkt. Möglicherweise finden diese Einsenkungen gerade an denjenigen Stellen statt, an welchen die Spalten und Kanäle des "kanalisirten“, hyalin umgewandelten Fibrins an der Oberfläche des Thrombus in die den letzteren umgebenden Lumenreste einmünden. In ihrer einfachsten Form bilden die Endotheleinsenkungen blindsackförmige Einstülpungen, die von der Oberfläche des Thrombus sich nur bis zu einer sehr unbedeutenden Tiefe zwischen die nächstgelegenen Gerinnseltheile hinein erstrecken. Ein'solches Vorkommniss ist in Fig. 3 bei 400 facher Vergrösserung wiedergegeben. Man sieht hier die freie, mit Endothel überzogene Oberfläche des Thrombus, sowie die endotheliale Einstülpung. In dem Lumen der letzteren finden sich einige rothe und ein weisses Blutkörperchen. Auch bemerkt man an einer Stelle unter dem Endothel der Thrombusoberfläche eine jener vielfach erwähnten Jugendformen von Bindegewebszellen.

In vorgerïckteren Stadien gehen seitlich von der Wand dieser primären Endotheleinsenkungen weitere Schlauchbildungen aus. Diese verzweigen sich in allen Richtungen, so dass man auf Schnittpräparaten nicht nur Längsschnitte sondern auch Querschnitte der mit Endothel ausgekleideten Kanäle antrifft. In letzterem Falle lässt sich constatiren, dass es sich um Kanäle mit rundlich gestalteten Lumen handelt. Dabei weisen die, diese Endothelröhren bildenden Zellen alle die Eigenschaften auf, welche die Endothelien der Thrombusoberfläche charakterisiren. Fig. 7 gestattet diese Verhältnisse bei schwächerer Vergrösserung zu verfolgen. Bei a ist die Intima der Venenwand wiedergegeben. Nach rechts folgt zunächst das spaltförmige Restlumen der Vene und sodann die mit Endothel bekleidete Thrombusoberfläche mit den zahlreichen kanalförmigen Endotheleinstiilpungen. Letztere durchsetzen hier einen Theil des Thrombus, welcher deutlich die Erscheinungen der hyalinen Umwandlung aufweist, und zugleich zahlreiche Wanderzellen einschliesst.

Bezüglich der Genese dieser Endotheleinstülpungen sind wir nicht im Stande erschöpfende Angaben zu machen. An manchen 
Stellen, wie z. B. in Fig. 3 gewinnt man den Eindruck, dass zunächst die Spitze des sich einsenkenden Endothelrohres offen ist, und in ähnlicher Weise sich auf den Oberflächen der in dem Fibrin vorhandenen Kanäle und Lücken vorschiebt wie die Endotheltapete auf der freien Thrombusoberfläche. Doch liegen hier Beobachtungsfehler sehr nahe, so dass wir diese Befunde vorläufig noch nicht als gesicherte betrachten möchten. An anderen Stellen dagegen, etwas tiefer im Thrombus, erscheinen die blinden Enden der Endotheleinsenkungen geschlossen und es gelang uns dann in einzelnen Fällen Erscheinungen der Sprossenbildung wahrzunehmen, wie sie bei der Neubildung von Capillaren namentlich von J. Meyer ${ }^{1}$ ), J. Arnold ${ }^{2}$ ) und von vielen späteren Autoren beobachtet wurden. Speciell an der Oberfläche von Thromben hat aber bereits Riedel ${ }^{3}$ ) solche von einem Endothelüberzug ausgehende Sprossenbildungen abgebildet und zwar auf Fig. $5 b$ seiner Tafel VI; doch bespricht er dieselben nur kurz und legt denselben keine besondere Bedeutung bei. Nach unseren Erfahrungen kommt die Sprossenbildung bei der Entwickelung der Endotheleinstülpung unzweifelhaft vor. In Anbetracht der eigenartigen Schwierigkeiten, welchen solche Untersuchungen unterliegen, muss es aber nach Obigem dahingestellt bleiben, ob nicht an einzelnen Stellen nahe der Oberfläche das Endothel ohne Vermittlung von Sprossen in die Spalten des Thrombus sich einschiebt.

Bei der weiteren Entwickelung der in den Thrombus eingedrungenen Endothelröhren ereignet es sich nicht selten, dass sich Communicationen und Anastomosen ausbilden zwischen benachbarten, von verschiedenen Punkten der Thrombusoberfläche herstammenden Röhren. In der Regel sind es die peripherischen Gerinnselschichten, welche eine solche Neubildung netzförmig verzweigter Capillaren aufweisen. Häufig findet man jedoch das Endothelröhrennetz über sehr weite Bezirke des Thrombus ausgedehnt; sie dringen häufig tief in die sonst noch alle Anzeichen einer Organisation entbehrenden Thrombusregionen vor. Wo,

1) J. Meyer, Annalen des Charité-Krankenhauses. Bd. IV. S. 41. 1853.

2) J. Arnold, Experimentelle Untersuchungen über die Entwickelung der Blutcapillaren. Dieses Archiv Bd. 53 u. 54.

3) Riedel, l. c. 
wie es in den peripherischen Zonen eines Thrombus meist $\mathrm{zu}$ geschehen pflegt, eine Zerfaserung der Thrombussubstanz in concentrisch geschichtete Bänder und Streifen stattgefunden hat, da halten auch die endothelialen Röhrensysteme einen der Oberfläche des Thrombus parallel gerichteten Verlauf ein; wo dagegen, wie es öfter in den mittleren Regionen, seltener in den peripherischen Schichten der Thromben anzutreffen ist, die (Terinnselmasse in unregelmässige Schollen und Bröckel zerklüftet. ist, da besitzen auch die endothelialen Schläuche eine sehr unregelmässige Gestaltung. Mit ziemlich gestreckten, von parallelen Wandungen begrenzten Röhren wechseln rundliche, kolbenund retortenförmige oder polygonale, mit ihren Ecken in breitere oder schmälere Fortsätze auslaufende Gebilde ab. In den verschiedensten Richtungen senden diese capillaren Bahnen bald kürzere, bald längere, zur Communication mit den benachbarten Röhrensystemen dienende, mit Endothel ausgekleidete Gänge ans, und überall in diesem ausgedehnten Systeme von neugebildeten Capillaren finden sich unzweifelhafte Spuren einer in demselben stattgefundenen Blutcirculation in Gestalt wohlconservirter Blatzellen. Das durch diese neugebildeten Gefässbahnen strömende Blut aber stammt offenbar aus den ursprünglich für den Blutstrom durchgängig gebliebenen oder aus den später, nach Schrumpfung des Thrombus wieder eröffneten Abschnitten der thrombosirten Venen.

Aus den vorstehenden Befunden ergiebt sich, dass von dem den Thrombus deckenden Endothelüberzuge aus ächte mit endothelialer Wand versehene Capillaren in die Masse des Thrombus hineinwuchern und daselbst vielfache Anastomosen unter einander eingehen. Damit ist die Einleitung gegeben zu weiteren gewebsbildenden Vorgängen. Zunächst treten an der Aussenfläche dieser Capillarbahnen wiederum jene eigenartigen Zellformen auf, welche sich durch ihre unregelmässig ovale Gestalt von den ausgebildeten Bindegewebszellen unterscheiden, und als unentwickelte Bindegewebszellen bezeichnet wurden. Dieselben sind in Fig. 8 bei sehr starker Vergrösserung abgebildet. Diese Zellen liegen um die äussersten Enden der Ausläufer der Capillarbahn in einer unterbrochenen Reihe angeordnet, zwischen dem Endothelrohr 
einerseits und den umgebenden Gerinnselmassen andererseits. An anderen Stellen (vergl. Fig. 8) gesellt sich za der erst gebildeten Zellreihe eine zweite, während zugleich die ersten Spuren von Intercellularsubstanz in der Umgebung dieser Zellen als feinstreifige oder homogene Massen nachweisbar werden. Deutlicher tritt die Intercellularsubstanz indessen erst hervor, wenn der Neubildungsprozess weiter vorgeschritten ist, und eine grössere Anzahl von Zellreihen gebildet sind. Es wird dann bemerklich, dass das junge Bindegewebe sich als eine Adventitia capillaris darstellt. Die Bindegewebszellen liegen in concentrischer Anordnung um die Capillaren und in gleicher Weise zeigt die Intercellularsubstanz eine mehr oder weniger deutliche concentrische Streifung und Schichtung. Dabei erscheinen die äusseren Schichten dieser adventitiellen Bildungen reicher an Intercellularsubstanz, die inneren Schichten dagegen relativ arm. In den äusseren Schichten findet man platte Zellformen, entsprechend den Bindegewebszellen des bindegewebigen Randsaumes des Thrombus, in den inneren Schichten dagegen die unentwickelten ovalen Zellformen, von welchen vielfach die Rede war.

Somit darf man als allgemeines Resultat aussprechen, dass auch von dem Endothel der in den Thrombus eingedrungenen Capillaren eine Bindegewebsneubildung ausgeht, welche bezüglich der Einzelheiten vielfache Uebereinstimmung darbietet mit den Neubildungsvorgängen, welche von dem den Thrombus überkleidenden Endothelhäutchen ihren Ursprung nehmen. Und auch hier überzeugt man sich an vielen Stellen von der Abwesenheit lymphoider Elemente. Doch finden sich allerdings auch im Gebiete der wuchernden Capillarschlingen zuweilen in grösserer Zahl Wanderzellen, welche entweder wohl erhalten sind oder verschiedenartige Erscheinungen des Zerfalles darbieten. In älteren Thromben aber nehmen die Bindegewebsneubildungen, welche in der Umgebung der Capillaren auftreten, allmählich in dem Grade an Masse zu, dass nur noch spärliche Reste von zerfallenen Thrombusmassen zwischen denselben übrig bleiben, und dass auch diese schliesslich verschwinden. Es sind dann grössere oder kleinere Abschnitte der Thrombusmassen vollständig durch Bindegewebe substituirt. In diesen Stadien aber treten in der Regel auch jene Gewebswucherungen im 
Thrombus deutlicher hervor, welche von den Vasa vasorum ausgehen, und den Abschluss des ganzen Prozesses bewirken. Diese sollen in dem folgenden Abschnitte genauer erörtert werden. Ehe wir uns jedoch zu denselben wenden, haben wir noch einiger Abweichungen von dem bisher geschilderten Verlaufe der Neubildungsprozesse zu gedenken.

In der vorstehenden Darstellung haben wir uns an den einfachsten Fall gehalten, in welchem die Verwachsungsstelle zwischen Thrombus und Gefässwand nur von sehr geringer Ausdehnung war. Vollständig nach demselben Princip erfolgt jedoch auch die von der Intima ausgehende und auf den Thrombus übergreifende Wucherung an solchen Querschnitten (Fig. 4), die nicht nur eine einzige, sondern mehrere oder sehr viele derartige Verwachsungsstellen aufweisen. Auch hier geht der Neubildungsprozess von den Anheftungsstellen des Thrombus an die Venenwand aus und verbreitet sich zunächst längs den freiliegenden, von der Venenwand durch blutführende Lücken getrennten $A b$ schnitten der Thrombusoberfläche, je näher jedoch die Anheftungsstellen zu einander liegen, und je mehr Ausgangspunkte sich der Endothelwucherung darbieten, desto rascher und vollkommener vollzieht sich die bindegewebige Umwachsung der freien Theile der Thrombuscircumferenz und desto rascher kommt es zu einer bindegewebigen Substitution der peripherischsten Thrombuslagen. Auf diese Weise stellen sich sämmtliche, ursprünglich zwischen Venenwand und Thrombusoberfläche gelagerten grösseren und kleineren blutführenden Spalträume allseits von Bindegewebe umgeben dar; überall führen sie auf der dem Lumen zugekehrten Oberfläche ihrer Wandungen eine Endothelzellenlage.

\section{Gefäss- und Bindegewebsbildung im Thrombus, ausgehend von den Vasa vasorum.}

Soweit wir die Vorgänge der Gewebsneubildung im Thrombus beschrieben haben, nehmen sie ihren Ausgangspunkt von dem Endothel der thrombosirten Vene. Eine Complication erfahren sie jedoch dadurch, dass gleichzeitig auch von den Vasa vasorum des thrombosirten Gefässes ber Neubildungen von Blutbahnen und Bindegewebe sich einleiten. Diese von den Vasa vasorum ausgehenden und an der bindegewebigen Substitution der Throm- 
ben Antheil nehmenden Prozesse beginnen ausschliesslich an denjenigen Stellen, an welchen die Thromben mit den Gefässwänden in Berührung stehen. Dabei richtet sich der Umfang, den die Betheiligung dieser Prozesse an der Gewebsbildung innerhalb der Gerinnselsubstanz gewinnt, zunächst nach der Zahl und der Ausbreitung dieser Contactstellen. Daher ist die Betheiligung der Vasa vasorum an solchen Strecken der thrombosirten Venen, welche Verhältnisse aufweisen, wie sie in den Querschnitten Figg. 1 und 2 abgebildet sind, eine geringere und es bleibt hier die Hauptleistung bezüglich der Substitution der intravasculären Gerinnselmassen durch blutgefässhaltiges Bindegewebe den bereits beschriebenen, von der Oberfläche der Thromben ausgehenden Prozessen überlassen. Umgekehrt ist den Vasa vasorum die Hauptaufgabe zuertheilt, an solchen Thromben, die, mit vielen oder allen Abschnitten ihrer Circumferenz mit der Intima in Berührung stehen, wie dies in Fig. 5 der Fall ist. Es erscheint daher zweckmässig, der Darstellung unserer Untersuchungsergebnisse zunächst die Verhältnisse der Fig. 5 zu Grunde zu legen.

Es handelt sich hier um einen ausgedehnten Thrombus der Vena femoralis superficialis, welcher in grosser Ausdehnung der Gefässwand dicht anliegt. Das Centrum des Thrombus in Fig. 5 enthält einen unregelmässigen Defect, indem beim Schneiden hier einige Theile herausfielen. Im Uebrigen zeigt diese Thrombusmasse eine schwache, diffuse Färbung mit Blutfarbstoff und eine feinkörnige Structur, in welcher man jedoch stellenweise noch Umrisse rother Blutkörper nachweisen kann. Auch einzelne weisse Blutkörper erscheinen hier und da zerstreat in den dichten körnigen Massen. Es dürfte somit hier ein rother Thrombus vorliegen, welcher bereits regressive Metamorphosen zeigt. Die Randzonen desselben enthalten einen reichen Kranz von Capillarschlingen und erseheinen zugleich stärker mit Blutfarbstoff durchtränkt. Letztgenannte Veränderung muss vielleicht in Zusammenhang gebracht werden mit Vorgängen der Diapedese rother Blutkörper, welche sich in den neugebildeten Capillarschlingen im Gefolge vorübergehender Stauungen des Blutes entwickelt hätten.

Nach aussen von dem Kranze von Capillarschlingen trifft man zunächst eine breite, in der Zeichnung hellgehaltene Zone, 
welche bis zur Tunica media der Gefässwand reicht. Diese helle Zone wird durch Bindegewebe gebildet, welches seiner Structur nach im Wesentlichen übereinstimmt mit dem Bindegewebe einer endophlebitisch verdickten Venenintima. Es wurde bereits früher erwähnt, dass die Intima thrombosirter Venen an den Contactstellen älterer Thromben in allen Fällen erheblich bindegewebig verdickt gefunden wurde. Dies trifft offenbar auch hier zo, wo der ganze Umfang der Gefässlichtung mit dem Thrombus in Contact verblieben ist.

Betrachtet man nun etwas genauer diese den Thrombus umhällende Bindegewebsmasse, so bemerkt man in derselben (Fig. 5) von Stelle zu Stelle etwas grössere mit Endothel ausgekleidete Hohlräume, in welchen man bei Anwendung stärkerer Vergrösserungen Reste von Blut nachweisen kann. Die topographischen Verhältnisse dieser Hohlräume, sowie ihre Gestalt machen es von vornherein höchst wahrscheinlich, dass in denselben Theile des ursprünglichen Venenlumen gegeben sind. Diese Meinung konnte in einigen Fällen bestätigt werden durch den Nachweis des Zusammenhanges dieser Räume mit den offenen Abschnitten des Lumen der Vene. Dem entsprechend würde man die Zone von Bindegewebe, welche diese Gruppe grösserer Gefässlacunen umkreist, als die verdickte Intima der Vene zu betrachten haben. Die Intervalle zwischen den Lacunen wären die hier sehr ausgedehnten Contactstellen und der Bindegewebsring, welcher in diese Gruppe von Hohlräumen eingeschrieben ist, würde aufgefasst werden müssen als das Product der bindegewebigen Substitution des Thrombus. Indessen hängen alle diese bindegewebigen Theile fest zusammen und bilden eine compacte ringförmige Zone um den Thrombus. Die äussere Grenze derselben ist glatt und wird durch die Tunica media der thrombosirten Vene gebildet. Die innere Grenze der Bindegewebszone ist dagegen von sehr unregelmässiger Gestalt. Es löst sich nehmlich der compacte Bindegewebsring an seiner inneren Begrenzung aut in zahlreiche, centripetal in den Thrombus hinein ziehende und vielfach mit einander anastomosirende Bindegewebszüge. Diese bilden in den Randschichten des Thrombus ein dichtes Maschenwerk, dessen Zwischenräume ausgefüllt werden von der beschriebenen, körnigen, stark blutig gefärbten Gerinnsèlsubstanz. 
Bei Anwendung stärkerer Vergrösserungen findet sich in der Axe jedes einzelnen Bindegewebszuges eine mit Endothel umsäumte Capillarschlinge. Je mehr sich die Endausläufer der Gefässe der noch nicht organisirten Thrombusmasse nähern, desto schmächtiger werden aber die die Gefässe begleitenden Bindegewebszüge; schliesslich fehlen dieselben vollständig. Es liegen dann die die Blutbahn umsäumenden Endothelröhren nackt in den Gerinnselmassen, wie dies in Fig. 6 abgebildet ist.

Macht man nun den Versuch, die Capillarschlingen und die sie einscheidenden Bindegewebszüge in der umgekehrten Richtung; vom Innern des Thrombus nach der Venenwand hin zu verfolgen, so sieht man die adventitièllen Scheiden der Capillarschlingen allmählich an Mächtigkeit zunehmen, und schliesslich in die compacten fibrösen Massen übergehen, welche in dem vorliegenden Organisationsstadium die äussersten Thrombuslagen ersetzt haben. Kleine Ansammlungen eines bräunlichen Pigments weisen nur hie und da inmitten der neugebildeten Bindegewebsmassen auf die frühere Anwesenheit von Thrombusmassen hin. Gleichzeitig aber überzeugt man sich, dass die Capillarschlingen in der Peripherie zum Theile einmünden in jene früher er. wähnten weiten, endothelumsäumten Blatlacunen, welche als Reste des ursprünglichen Venenlumen zu betrachten sind. Ein anderer Theil der Capillarschlingen jedoch steht in directem $\mathrm{Zu}$ sammenhang mit einer Anzahl von kleinen Blutgefässen, welche von der Adventitia herstammen, die Media durchbrechen und in der bindegewebig verdickten Intima sich verzweigen.

Diese Communicationen zwischen den Capillarschlingen einerseits und den Vasa vasorum andererseits lassen sich an nicht injicirten Dünnschnitten, wie sie uns vorlagen, nicht immer so vollständig verfolgen, dass man den directen Zusammenhang zwischen den Gefässen der Adventitia der thrombosirten Vene und den Capillaren des Thrombus ohne jegliche Unterbrechung in einem Schnitte aufweisen kann. Doch ist es uns wiederholt gelungen den in Rede stehenden Zusammenhang in dieser Weise zur Anschauung zu bringen. In der Regel stellen sich die Verhältnisse in der Weise dar, wie dies in Fig. 9 abgebildet ist. Diese Figur stammt nicht aus der Vene, welche der Fig. 5 zu Grunde gelegt ist. Die Abbildung wäre ausserordentlich gross 
geworden, wenn wir aus der Vene der Fig. 5 den Rand des Thrombus und die ganze Dicke der Gefässwand hätten bei genügend starker Vergrösserung zeichnen wollen. Wir wählten daher einen Schnitt aus einer Vena jugularis interna, welche sehr dünne Wände besass, um ihn in Fig. 9 wiederzugeben. In dieser Figur unterscheidet man zunächst oben und rechts eine dunklere körnige Masse, einen Theil des Thrombus. An diese Reste des Thrombus schliesst sich eine Zone hellen, von zahlreichen Capillarbahnen durchzogenen Bindegewebes. Letzteres reicht nach unten bis zu einer Grenze, welche durch die Verbindungsinien der Blutlacunen a, a, a gegeben ist. Weiter abwärts folgt eine streifige Zone, die Tunica media, die endlich an die ziemljch homogene Adventitia angrenzt.

In der Adventitia finden sich eine Anzahl von Vasa vasorum, von denen zwei mit dem Buchstaben $b$ bezeichnet sind. Aber auch die Media ist reich an weiten Blutbahnen. Aus diesen lassen sich drei stärkere Stämmchen zusammensetzen, welche die Media durchbrechen und mehr oder weniger weit in die Bindegewebsmassen eindringen, die den äusseren Rand des Thrombus ersetzt haben. Hier liegen dann neben zahlreichen Durchschnitten von Capillaren die drei grösseren Blutlacunen a, a, a,-welche als Reste des ursprünglichen Venenlumen betrachtet werden müssen. Bei der Durchsicht zahlreicher Schnitte aus diesen Regionen des Thrombus konnte man sich ferner davon überzeugen, dass die neugebildeten, an Stelle der Randzonen des Thrombus liegenden Capillaren vielfach mit diesen Blutlacunen in offenem Zusammenhange stehen.

Wenn man sich nun eine Vorstellung zu bilden versucht von den Circulationsverhältnissen in diesen Gefässbahnen, welche die Thrombusmassen umsäumen, so liegt es nahe anzunehmen, dass das Blut von den Vasa vasorum her einströmt, das weite Capillarnetz in den Randzonen des Thrombus durchfliesst um schliesslich durch die Lacunen a in das Venensystem überzutreten. Möglicherweise ist dies nicht der einzige $W$ eg, welcher dem Blute offensteht. Es wäre möglich, dass sich auch Verbindungen zwischen dem Capillarnetz des Thrombus und den venösen Vasa vasorum ausbilden. Diese Möglichkeit ist aber in vorliegendem Präparate nicht nachzuweisen. Mit Bestimmtheit 
lässt sich nur behaupten, dass eine regelmässige Circulation zwischen den Vasa vasorum und den Resten des Venenlumen sich einleiten muss, sowie diese beiden Theile durch die neugebildeten Capillaren in Verbindung getreten sind. Diese Verbindung war mit den gegebenen Mitteln nachzuweisen.

Es findet aber das gewonnene Resultat eine Analogie in den Untersuchungen von 0 . Weber ${ }^{1}$ ) und Th. Kocher ${ }^{2}$ ). Diese hatten die Gefässneubildung untersucht in Thromben ligirter Arterien und dabei nachgewiesen, dass zwischen dem Lumen der ligirten Arterie einerseits und deren Vasa vasorum andererseits durch Capillaren eine Verbindung hergestellt wird, welche einen Blutstrom aus dem Arterienlumen in die venösen Vasa vasorum abzuleiten geeignet war. Es ist demgemäss anzunehmen, dass in thrombosirten Arterien und Venen analoge Gefüssneubildungen im Thrombus erzeugt werden, mit dem Unterschiede, dass in beiden Fällen der Blutstrom in den neuangelegten Bahnen verschiedene Richtungen besitzt. Doch wird man in beiden Fällen, ausgedehnte, vollkommen obturirende Thromben vorausgesetzt, die Möglichkeit nicht ausschliessen dürfen, dass von den Vasa vasorum her sich in den Thrombus hinein Capillarschlingen und grössere Blutbahnen bilden können, welche von arteriellen Vasa vasorum gespeist, ihr Blut in venöse Vasa vasorum entleeren. Und für die frühesten Stadien, so lange die Gefässneubildung, welche von den Vasa vasorum ausgeht, noch nicht in Verbindung getreten ist mit den Capillaren, welche von dem Endothel des Restlumen des thrombosirten Gefässes herstammen, wird man ein solches Vorkommniss in der Regel annehmen müssen. Wirklich beobachtet haben wir solche Verhältnisse nur in einigen später zu beschreibenden Thromben, welche sehr kleine Contactstellen mit der Venenwand aufwiesen.

Ehe man sich zu der Betrachtung dieser letzteren wendet, erscheint es angezeigt, den Einzelheiten der von den Vasa vasorum ausgehenden Gefässneubildung noch einige Aufmerksamkeit zu widmen. Es wurde bei der Beschreibung der Fig. 5

1) 0. Weber, Handbuch der allg. u. spec. Chirurgie von Pitha und Billroth. Bd. I. Abth. I. S. 139.

2) Th. Kocher, Ueber die feineren Vorgänge bei der Blutstillung durch Acupressur, Ligatur und Torsion. Archiv f. klin. Chirurgie. Bd. XI. 1869. 
bereits erwähnt, dass die innerste Zone der von der Gefässwand ausgehenden Gewebswucherung aus Capillarbahnen besteht, deren Wand ausschliesslich aus Endothel gebildet wird. Solche $\mathrm{Ca}$ pillaren sind in Fig. 6 bei stärkerer Vergrösserung abgebildet. Sie enthalten einzelne rothe Blutkörper, die in der Zeichnung als lichte Kreise erscheinen, sowie einige dunkler gehaltene, weisse Blutzellen. Zwischen den Capillaren erscheint die dunkle Masse des Thrombus wiederum von einigen rothen und weissen Blutkörpern durchsetzt. Diese Capillaren wachsen durch Sprossenbildung. Doch sind die Gefässsprossen hier schwer nachweisbar, in Folge der trüben, körnigen Beschaffenheit der geronnenen Massen, welche die Capillaren umgeben. Näher der Wand der thrombosirten Vene findet man dieselben Capillaren, jedoch belegt von einzelnen jener jugendlichen Bindegewebszellen, welche im ersten Abschnitte dieser Arbeit genauer beschrieben wurden. Alsdann entwickelt sich eine Adventitia capillaris in Form einer dünnen, die Capillare concentrisch umhüllenden Bindegewebsschicht. Und in den äussersten Theilen der den Thrombus ersetzenden Gewebsmasse werden diese adventitiellen Bekleidungen der Capillaren mächtiger und gehen endlich ohne scharfe Grenze in die compacten Bindegewebsmassen über, welche die Peripherie des Thrombus umsäumen.

In sehr übersichtlicher Weise lassen sich diese Verhältnisse auch verfolgen auf dem Venenquerschnitte der Fig. 4. Es handelt sich hier um eine ältere Thrombose der Vena tibialis postica. In der Abbildung bemerkt man nach innen von der etwas dunkler gehaltenen Tunica media zunächst die elastischen Elemente und sodann die neugebildeten Bindegewebsschichten der Intima. Diese werden an vielen Stellen nach innen zu abgegrenzt durch relativ grosse, mit Endothel ausgekleidete, blutführende Räume, die Reste des ursprünglichen Venenlumen. Der grössere Theil des letzteren ist aber von der theilweise bindegewebig substituirten Thrombusmasse ausgefüllt. Die Reste des Thrombus sind feinkörnig, dunkel gehalten. Sie werden von breiteren und schmäleren Bindegewebszügen durchsetzt, welche in ihrer Axe Capillargefässe enthalten. Wenn man bemerkt, dass auch die verdickte Intima Querschnitte von kleinen Blutbahnen aufweist, so dürfte die Deutung des ganzen Bildes nicht schwer fallen. Dasselbe giebt eine 
gute Illustration des früher Gesagten und zeigt zugleich, wie die Verhältnisse sich ändern, wenn der Thrombus nur mit einem Theile seines Umfanges dauernd in Berührung bleibt mit der Gefässwand.

Verfolgt man endlich die gleichen Vorgänge an solchen Thromben, welche wie in Fig. 1 und 2 nur sehr kleine Contactstellen mit der Venenwand aufweisen, so tritt, wie bereits früher erwähnt, die von den Vasa vasorum ausgehende Gefässneubildung weniger reichlich hervor. Sie bleibt indessen nicht aus, ihr Auftreten ist nur verzögert, und wird erst bemerkbar, wenn der grössere Theil der Peripherie des Thrombus bereits von dem Endothel der thrombosirten Vene her mit Bindegewebe umkleidet ist. Zunächst erscheint Media und Intima an der Contactstelle reichlicher vascularisirt. Dann treten einzelne Gefässschlingen aus der Intima in den Thrombus über. In diesem Stadium gelang es uns nicht, einen Zusammenhang der von den Vasa vasorum ausgehenden Gefässschlingen mit den Resten des Venenlumen nachzuweisen. Dies gelingt erst später, wenn von der Contactstelle her eine ergiebigere Vascularisation des Thrombus eingeleitet ist. Man findet dann zugleich in der Contactstelle relativ weite Blutbahnen in den Thrombus übertreten, welche eine deutliche Ringmusculatur aufweisen, und somit die Charaktere von kleinen Arterien besitzen. Diesen lassen kaum einen Zweifel darüber, dass nun relativ ${ }_{i}$ reichliche Blutmengen aus den Vasa vasorum in die Capillaren, welche den Thrombus durchziehen, einströmen, um durch diese hindurch in das Restlumen der Vene sich zu ergiessen. In der Regel aber zeigten sich selbst in den letzten Stadien, in einer Zeit in welcher der Thrombus fast in seiner ganzen Ausdehnung durch Bindegewebe ersetzt war, immer noch geringe Mengen von hyalin umgewandeltem Fibrin zwischen den Capillaren und Bindegewebszügen, welche den Thrombus durchsetzten. Nur in wenigen Fällen konnten wir eine vollständige Substitution des Thrombus durch Bindegewebe beobachten. Es ist dies begreiflich, wenn man erwägt, wie lange sich auch nach Erfahrungen anderer Autoren Reste von Fibrin im Gefässsystem erhalten können. Es sind dann nur noch geringe Mengen von bräunlichem Pigment, welche hier und da zerstreut an die verschwundenen Blatcoagula erinnern. 
Versucht man in wenigen Worten die gewonnenen Ergebnisse bezüglich der Substitution marantischer Thromben durch Bindegewebe zusammenzufassen, so wendet sich das Interesse zunächst dem Verhalten des Thrombus zu.

Die ersten Veränderungen, welche an dem Thrombus bemerkbar werden, charakterisiren sich als eine Umwandlung desselben in feinkörnige oder hyaline Massen. Diese zeigen in der Regel, zum Theil entsprechend der ursprünglichen Schichtung des Thrombus, mehr oder weniger ausgiebige Zerklüftung durch zahlreiche feine Spalten. Die Thrombusmasse nimmt den Charakter des "kanalisirten Fibrins" an. Dabei kommt es vor, dass in diese Spalten von Neuem die Elemente des Blutes eingeschoben werden, um abermals zu zerfallen. Gleichzeitig verkleinern sich, wie es scheint, die äusseren Durchmesser des Thrombus; derselbe unterliegt einer Schrumpfung. Jedenfalls findet man auch bei anscheinend obturirenden Thromben grössere und kleinere cylindermantel- oder spaltförmige, blutführende Räume zwischen einzelnen Theilen der Venenwand and der Thrombusoberfläche. Allein diese Räume zeigen vielfache Unterbrechungen, indem der Thrombus an gewissen Stellen dauernd in Contact bleibt mit der Venenwand.

Die ersten zur bindegewebigen Substitution des Thrombus gehörigen Veränderungen gehen von diesen blutführenden in der Peripherie des Thrombus gelegenen Räumen aus. Diese kleiden sich mit Endothel aus, welches abstammt von dem Endothel der thrombosirten Vene. Letzteres geräth in Wucherung und überzieht von den Contactstellen aus die zuweilen sehr grossen, freien, den genannten Bluträumen zugewendeten Oberflächen des Thrombus. Der Endothelwucherung auf der Thrombusoberfläche folgt eine Bindegewebsneubildung, welche gleichfalls ihren Ausgangspunkt nimmt von den Contactstellen. Alle Verhältnisse sprechen dafür, dass bei diesem Vorgange die Bindegewebszellen aus den Endothelien hervorgehen. Das neugebildete Bindegewebe aber gewinnt allmählich an Dicke und bildet nun eine relativ breite Bindegewebshülle, welche immer vom Endothel bedeckt, den Thrombus überkleidet. - Aus dem Endothelüberzug des Thrombus gehen fernerhin Capillaren hervor. Diese senken sich von der freien Fläche aus in die Thrombusmasse 
hinein. Sie verzweigen sich im Thrombus and entwickeln zunächst eine Adventitia capillaris, welche späterhin durch weiteres Wachsthum in dickere Bindegewebszüge übergeht.

Eine zweite Gruppe von Capillarschlingen gebt aus den Vasa vasorum hervor. Diese treten in den Thrombus ein an denjenigen Stellen, an welchen der Thrombus mit der Venenwand dauernd in Contact geblieben ist; sie verzweigen sich sodann in der Thrombusmasse, und an ihrer Aussenfläche entwickelt sich in gleicher Weise eine Adventitia capillaris, welche späterhin in mächtigere Bindegewebsmassen sich umwandelt. Die zwei ihrem Ausgangspunkte und ihrem primären Ausbreitungsbezirke nach getrennten Capillargefässsysteme treten in der Folge mit einander in Verbindung. Die Capillaren, welche von den Vasa vasorum entstanden sind, haben vorzugsweise die centralen Abschnitte des Thrombus durchwachsen. Indem sie nun mit den Capillaren der Randzone des Thrombus, welche von dem Endothel der Thrombusoberfläche herstammen, zusammenfliessen, stellt sich die Verbindung her zwischen den Vasa vasorum einerseits und den freigebliebenen Theilen des Lumen der thrombosirten Vene andererseits.

Die weiteren Veränderungen beschränken sich nun darauf, dass die vorhandenen Bindegewebszüge an Mächtigkeit zunehmen, während in demselben Maassstabe die Ueberreste des Thrombus schwinden. Als letztes Umwandlungsproduct des in den Gerinnseln enthaltenen Blutfarbstoffes bemerkt man zuweilen noch einige braune, körnige Pigmentmassen - hämatogenes Pigment - vermuthlich Eisenoxydhydrat.

Diese Vorgänge zeigen mannichfache Analogien mit dem Auftreten der Capillaren im Embryo. In die hyaline Thrombusmasse, welche mehr oder weniger vollständig der zelligen Elemente entbehrt, wachsen die Capillaren und die Bindegewebszüge in ähnlicher Weise hinein, wie nach den Erfahrungen von His in den Körper des Embryo. Somit findet auch der hier betrachtete pathologische Vorgang, die Organisation der Thromben, ein Vorbild auf physiologischem Gebiet. Die Ergebnisse der physiologischen und der pathologischen Untersuchung aber dienen sich gegenseitig zur Bestätigung. 


\title{
Erklärung der Abbildungen.
}

\author{
Tafel VII.
}

Fig. 1: Thrombose der Vena femoralis superficialis. Der Thrombus hat sich nahezn in seinem ganzen Umfange von der Venenwand zurückgezogen und ist mit einer Zone von Endothel und Bindegewebe umkleidet, welche mit dem Endothel und dem Bindegewebe der Intima zusammenhängt. Vergr. 9.

Fig. 2. Thrombose der Vena femoralis superficialis, äbereinstimmend mit Fig. 1, jedoch an einer Stelle der Vene, welche die Querschnitte zweier Venenklappen aufweist. Die Tasche der einen Klappe ist theilweise bindegewebig obliterirt. Vergr. 9.

Fig. 3. Einsenkung des Endothels der Thrombusoberfläche in die Substanz des Thrombus. Vergr. 400.

Fig. 4. Bindegewebige Substitution eines Thrombus der Vena tibialis postica. Vergr. 11.

Fig. 5. Bindegewebige Substitution eines Thrombus der Vena femoralis superficialis. Vergr. 11.

Fig. 6. Neugebildete Capillarbahnen in einem Thrombus. Vergr. 310.

Fig. 7. Endotbeleinstülpung an der Oberfläche eines Thrombus der Vena jugularis externa. Daneben ein Abschnitt der Venenwand a und ein Theil des spaltförmigen Restlumen. Vergr. 140.

Fig. 8. Capillarbahn und jugendliche Bindegewebszellen in der peripherischen Zone eines Thrombus, entstanden durch Wucherung der endothelialen Unkleidung. Vena femoralis superficialis. Vergr. 440.

Fig. 9. Von den Vasa vasorum herstammende Gefässbahnen in den Raudpartien eines obturirenden Thrombus der Vena jugularis externa. Vergr. 240, 